\title{
Detection of Bovine Lactoferrin Binding Protein on Jurkat Human Lymphoblastic T Cell Line
}

\author{
Tetsuya TANAKA ${ }^{1)}$, Hiroshi MORITA ${ }^{1)}$, Yung-Choon YOO $^{2)}$, Woan-Sub KIM ${ }^{1)}$, Haruto KUMURA ${ }^{1)}$ and \\ Kei-ichi SHIMAZAKI ${ }^{1)}$ \\ ${ }^{1)}$ Dairy Science Laboratory, Graduate School of Agriculture, Hokkaido University, Sapporo, Hokkaido 060-8589, Japan and \\ ${ }^{2)}$ Department of Microbiology, Konyang University School of Medcine, Nonsan, Chungnam 320-711, Korea
}

(Received 10 July 2003/Accepted 9 February 2004)

ABSTRACT. Lactoferrin (Lf), a member of the transferrin family protein, is an iron-binding protein that is known to interact with mammalian cells through a specific receptor. We examined binding of Lf to Jurkat human lymphoblastic T cell line (Jurkat cells) by far Western blotting, and found that bovine Lf and human Lf bound to the same protein components of Jurkat cells, and that pepsin digestion of Lf disrupts the sites responsible for binding to cellular proteins. We also found that the sugar chains of bovine Lf are not involved in binding between bovine Lf and Jurkat cells. Bovine Lf, bovine transferrin and ovotransferrin bound to the same proteins of Jurkat cells, which had molecular weights of about $35 \mathrm{kDa}$.

KEY WORDS: Jurkat human lymphoblastic T cell line, lactoferrin, transferrin family protein.

J. Vet. Med. Sci. 66(7): 865-869, 2004

Lactoferrin (Lf), an iron-binding glycoprotein with a molecular weight of about $80 \mathrm{kDa}$, is found in milk, saliva, tears, mucus secretions and neutrophil granules. Lf belongs to the transferrin (Tf) family of proteins, which includes serum Tf and ovotransferrin (OTf). Human milk is particularly rich in Lf [19]. Bovine milk also contains Lf [10]. It has been reported that Lf has various biological functions, including anti-microbial activity [1,9], anti-virus activity [11], anti-parasite activity [23, 24], anti-inflammation activity [5] and anti-cancer activity [25]. These activities play important roles in host defense and homeostasis.

Lactoferrin-binding proteins have been found on the surface of various cells, including hepatocytes, erythro-leukemic cells, monocytes, peritoneal macrophages, activated Tcells and platelets, and on the surface of various microorganisms $[6,20]$. Lf receptors have also been found on the intestinal brush border [12, 13, 18, 22]. The finding that various immune-related cells (Jurkat human lymphoblastic $\mathrm{T}$ cell line) have $\mathrm{Lf}$ receptors on their surface suggests that Lf has receptor-mediated effects on these cells $[2,4,7,16]$.

Studies of the effects of Lf on T-cell modulation can be expected to provide important information about the Lf receptor. Lf-mediated control of inflammation could potentially be used for various applications of immunosuppression such as relief of organ transplant rejection. The purpose of the present study was to detect Lf binding proteins on Jurkat human lymphoblastic $\mathrm{T}$ cell line (Jurkat cells). And the binding properties of Lf and other Tf family proteins were compared, because it has been reported that, on other cells, Lf receptors are different from Tf receptors. We used bovine Lf (BLf) because it is readily separated from bovine milk, and because of its high homology with human Lf (HLf). Recently, the necessity of alternative medicine has come to be recognized, especially in the U.S.A. Bovine Lf may have potential as an alternative medicine, due to its high biological activity. Medical application of BLf may greatly increase the value of bovine milk.

The following materials were obtained: herbimycin A, aprotinin and leupeptin (Wako Pure Chemical Industries Ltd., Osaka); phenylmethanesulfonyl fluoride, N-hydroxysuccinimide biotin, fluorescein-conjugated avidin (avidinFITC), bovine serum albumin (BSA), apo HLf, apo bovine Tf (BTf) and OTF (iron free) (Sigma Chemical Co., St. Louis, MO); horseradish peroxidase-conjugated streptavidin (streptavidin-HRP) (Nichirei Co., Tokyo); RPMI 1640 medium (IRVINE Scientific Johnson Matthey plc, Santa Ana, CA); streptomycin (Meiji Seika Co., Tokyo); penicillin (Banyu Seiyaku Co., Tokyo); apo BLf and pepsin lysate of BLf (Morinaga Milk Co., Tokyo); ECL reagent kit (Amersham Bioscience Co., Piscataway, NJ, used to detect chemiluminescence).

The Jurkat cells were maintained at $37^{\circ} \mathrm{C}$ in a $5 \% \mathrm{CO}_{2}$ atmosphere in RPMI1640 culture medium supplemented with 5\% fetal bovine serum (FBS), $0.04 \mathrm{mM}$ 2-mercaptoethanol, $0.08 \mathrm{~g}$ (titer)/liter streptomycin and 80,000 unit/liter penicillin. For cell harvesting, the cell culture was centrifuged and the supernatant was removed. The pelleted cells were washed 3 times with phosphate-buffered saline (PBS). Finally, the cells were distributed into fresh tubes at $1 \times 10^{7}$ cells per tube. The tubes containing Jurkat cells were stored at $-80^{\circ} \mathrm{C}$ until the cells were used.

The membrane and cytosolic proteins were extracted from Jurkat cells by the following method. First, the cell pellets were suspended in enzyme inhibitor solution $(50 \mu \mathrm{l} /$ tube) containing $0.1 \mathrm{mM}$ sodium vanadate, $0.5 \mu \mathrm{g} / \mathrm{m} l$ herbimycin A, $50 \mu \mathrm{g} / \mathrm{m} l$ aprotinin, $25 \mu \mathrm{g} / \mathrm{m} l$ leupeptin, $750 \mu \mathrm{g} / \mathrm{m} l$ benzamidine and $1 \mathrm{mM}$ PMSF in Dulbecco's phosphatebuffered saline (DPBS; $\mathrm{Ca}^{2+} / \mathrm{Mg}^{2+}$-free). The cells were then lysed by freeze/thawing, which consisted of freezing the cells in liquid $\mathrm{N}_{2}$ and then immediately thawing them at 
$37^{\circ} \mathrm{C}$; this was repeated 5 times. Next, the cell lysates were centrifuged at $11,000 \mathrm{~g}$ for $10 \mathrm{~min}$; the resultant supernatant contained the cytosolic fraction, then the pellets were washed 3 times with appropriate buffer, once with $1 \mathrm{ml}$ of enzyme inhibitor solution and twice with $1 \mathrm{ml}$ of cold PBS. In the final step, proteins (membrane-associated fraction) were extracted from the pellets with $50 \mu \mathrm{l}$ of lysis buffer containing $1 \%$ Triton X-100 and 1\% CHAPS in enzyme inhibitor solution. Extraction of whole cell proteins from Jurkat cells was performed as follows. The cell pellets were suspended in lysis buffer containing 1\% Triton X-100 and $1 \%$ CHAPS in enzyme inhibitor solution. After cooling for $15 \mathrm{~min}$ on ice, centrifugation was performed at 13,000 $\mathrm{g}$ for $15 \mathrm{~min}$; the resultant supernatant contained the whole cell protein fraction.

To prepare biotinylated proteins, N-hydroxysuccinimide biotin was dissolved at a concentration of $10 \mathrm{mg} / \mathrm{ml}$ in dimethyl sulfoxide, and the proteins (apo-BLf, apo-HLf, apoBTf or OTF) were dissolved at a concentration of $3 \mathrm{mg} / \mathrm{m} l$ in $0.1 \mathrm{M}$ sodium borate buffer $(\mathrm{pH} 8.8)$. The biotin ester was then added at a ratio of $250 \mu \mathrm{g}$ of biotin ester per $1 \mathrm{mg}$ of protein, followed by mixing well and incubation at room temperature for $4 \mathrm{hr}$. Next, $20 \mu \mathrm{l}$ of $1 \mathrm{M} \mathrm{NH}_{4} \mathrm{Cl}$ per $250 \mu \mathrm{g}$ of biotin ester was added, and the solution was incubated at room temperature for $10 \mathrm{~min}$. After incubation, the reaction mixture was dialyzed extensively against PBS to remove the unreacted reagent. The estimated biotinylation ratio was $32 \%$ of total amino groups, based on molecular mass measured from the matrix-assisted laser desorption ionizationtime of flight mass spectrum.

Far Western blotting was carried out as follows. Sodium dodecyl sulfate polyacrylamide gel electrophoresis (SDSPAGE) analysis was performed on a $10 \%$ polyacrylamide gel, by Laemmli's method [15]. Before electrophoresis, the proteins were boiled for $5 \mathrm{~min}$ in sample buffer $(62.5 \mathrm{mM}$ Tris- $\mathrm{HCl}$ (pH 6.8), 2\% SDS, 5\% beta-mercaptoethanol, $10 \%$ glycerol, $0.02 \%$ bromophenol blue). After SDSPAGE, the proteins were blotted onto a PVDF membrane (Osmonics Inc., Westborough, MA). Electroblotting was performed at $2 \mathrm{~mA} / \mathrm{cm}^{2}$ for $1 \mathrm{hr}$ at room temperature in 25 mM Tris, $192 \mathrm{mM}$ glycine and $20 \%$ ethanol buffer. The blotted PVDF membrane was blocked with the blocking buffer (2\% BSA and $0.1 \%$ Tween 20 in PBS). After blocking, the membrane was incubated with biotinylated proteins at a concentration of $1 \mu \mathrm{g} / \mathrm{m} l$ in blocking buffer at $4^{\circ} \mathrm{C}$ overnight. The membrane was washed 5 times in washing buffer $(0.5 \%$ Tween 20 in saline) and incubated at room temperature for $30 \mathrm{~min}$ with streptavidin-HRP diluted to 1:800 in the blocking buffer. The membrane was then washed 5 times in washing buffer, and the protein bands were visualized on Xray film with an ECL kit according to the manufacturer's protocol.

A competitive inhibition assay by far Western blotting was performed as follows. The blotted PVDF membrane, treated as described above, was blocked with the blocking buffer. After blocking, the membrane was incubated with BLf, HLf, or pepsin lysate of BLf at a concentration of 500 $\mu \mathrm{g} / \mathrm{m} l$, or with $\mathrm{N}$-acetyl-D-glucosamine, N-acetyl-D-galactosamine, $\mathrm{D}(+)$-mannose or lactose at a concentration of 100 $\mathrm{mM}$ in the blocking buffer, at room temperature for $30 \mathrm{~min}$. Biotinylated proteins were then added to the inhibitor solution at a concentration of $1 \mu \mathrm{g} / \mathrm{m} l$, and the membrane was incubated at $4^{\circ} \mathrm{C}$ overnight. The membrane was then washed 5 times in washing buffer and incubated at room temperature for $30 \mathrm{~min}$ with streptavidin-HRP diluted to 1:800 in blocking buffer. Next, the membrane was washed 5 times in washing buffer, and the protein bands were visualized on X-ray film with the ECL kit according to the manufacturer's protocol.

Far Western blotting analysis was performed to compare patterns of binding to whole cell proteins of Jurkat cells in biotinylated BLf (BLf-bio) and biotinylated HLf (HLf-bio). There were several bands that bound both BLf-bio and HLfbio; none of these bands also bound streptavidin-HRP only (Fig. 1).

To assess whether BLf-bio and HLf-bio recognize the same proteins, competitive inhibition assay by far Western blotting was performed. As shown in Fig. 2 (1), BLf inhibited binding of BLf-bio to whole cell proteins of Jurkat cells (lane C), but HLf (lane B) and pepsin lysate of BLf (lane D) had no inhibitory effect. Based on these findings, we performed the competitive inhibition assay for binding of HLf-

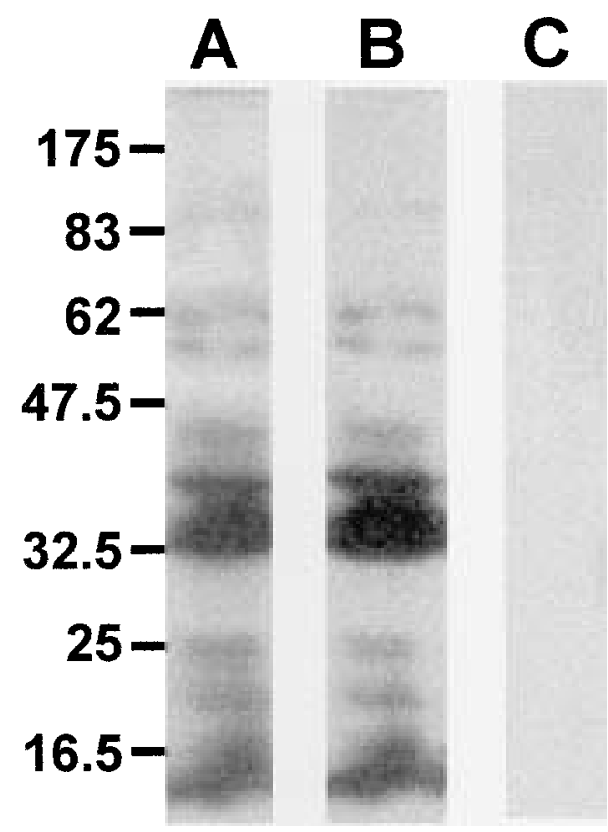

Fig. 1. Binding of BLf-bio or HLf-bio to whole cell proteins of Jurkat cells. Whole cell proteins extracted from Jurkat cells were subjected to SDSPAGE under reducing conditions and electrotransferred to PVDF membrane. After incubation with BLf-bio (lane A), HLf-bio (lane B) or streptavidin only (lane C) at a concentration of $1 \mu \mathrm{g} / \mathrm{ml}$, the binding proteins were detected with streptavidinHRP. The positions of protein molecular mass standards are indicated at the left, in $\mathrm{kDa}$. 


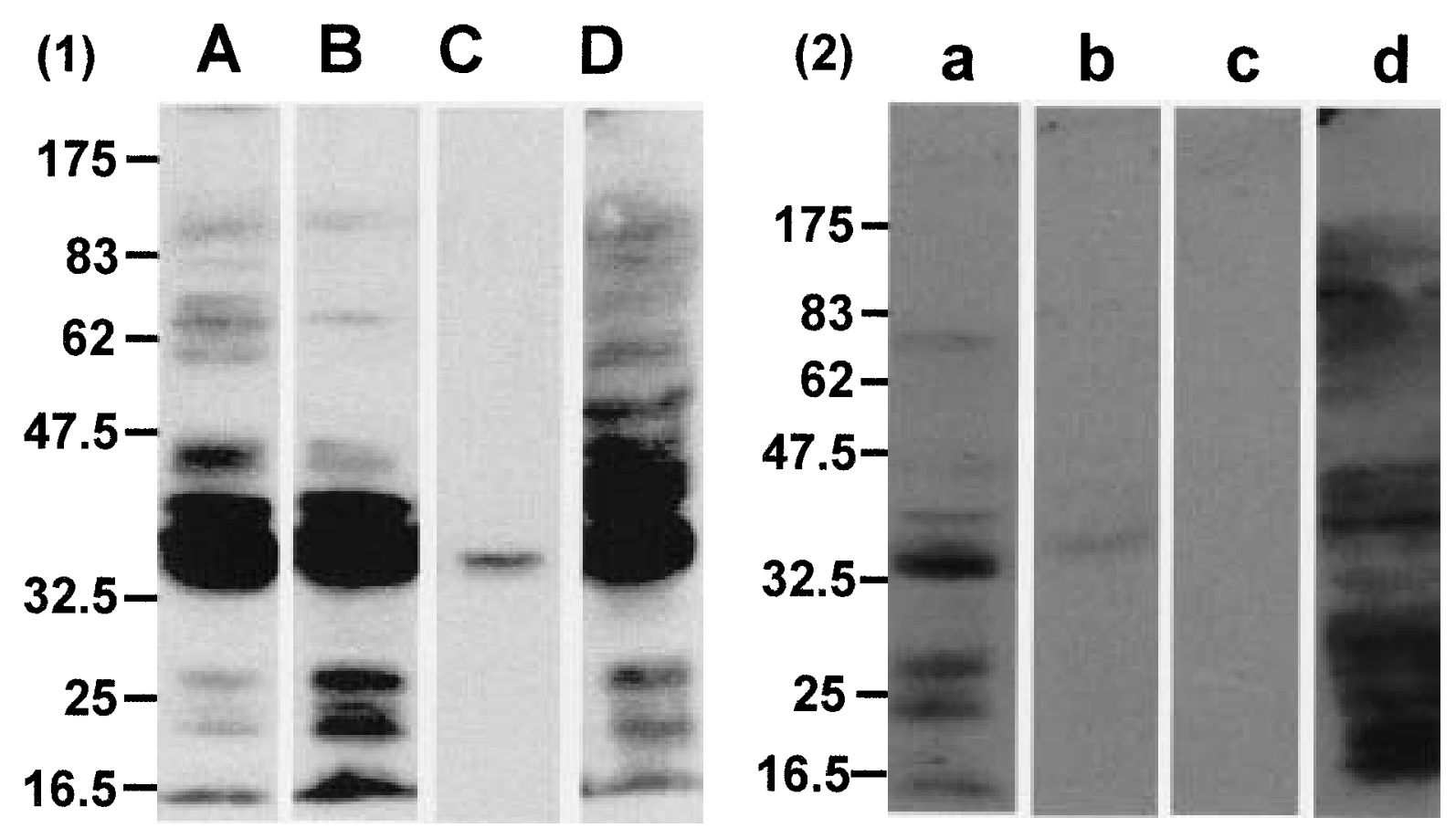

Fig. 2. Comparison of binding to whole cell proteins of Jurkat cells between BLf-bio (1) and HLf-bio (2). Whole cell proteins extracted from Jurkat cells were subjected to SDS-PAGE under reducing conditions and electrotransferred to PVDF membrane. After incubation with BSA (lane A, a), HLf (lane B, b), BLf (lane C, c) and pepsin lysate of BLf (lane D, d) at a concentration of $500 \mu \mathrm{g} / \mathrm{ml}$, incubation with BLf-bio (lane A, B, C, D) or HLf-bio (lane a, b, c, d) at a concentration of $1 \mu \mathrm{g} / \mathrm{m} l$ with the inhibitors was performed. Detection was performed with streptavidin-HRP. The positions of protein molecular mass standards are indicated at the left, in $\mathrm{kDa}$.

bio to the whole cell proteins of Jurkat cells. As shown in Fig. 2 (2), HLf (lane b) and BLf (lane c) inhibited binding of HLf-bio to whole cell proteins of Jurkat cells, but pepsin lysate of BLf had no inhibitory effect (lane d).

To assess whether the carbohydrate chains of Lf are involved in binding of Jurkat cells, a competitive inhibition assay was performed but $\mathrm{N}$-acetyl-D-glucosamine, $\mathrm{N}$ acetyl-D-galactosamine, D (+)-mannose (lane D) and lactose had no inhibitory effect on binding of BLf to the proteins of Jurkat cells (Data not shown).

Figure 3 shows the results of the binding assay of cytosolic and membrane proteins of Jurkat cells by far Western blotting. Lane A shows the binding pattern of membraneassociated fraction with BLf-bio as the first ligand: there were 2 distinct bands around $35 \mathrm{kDa}$. For biotinylated BTf (BTf-bio) (lane B) and biotinylated OTf (OTf-bio) (lane C), there were 2 distinct bands around $35 \mathrm{kDa}$ that were very similar to those observed for BLf-bio.

In this study, we examined the Lf binding proteins on the cell surface of Jurkat cells. A major tool for the detection of protein-ligand interaction is biotinylated protein. Binding of BLf-bio and HLf-bio to whole cell proteins of Jurkat cells was examined by far Western blotting, as shown in Fig. 1. There was no non-specific binding of streptavidin-HRP to whole cell proteins of Jurkat cells. The results suggest that BLf-bio and HLf-bio recognize the same proteins of Jurkat cell. To test this possibility, a competitive inhibition assay was performed. Before the transferred membrane was incubated with the first ligand, it was incubated with inhibitor solution. The first ligand only binds to protein bands that are not recognized by the inhibitor. The results show that BLf-bio and BLf recognize the same proteins, and that HLfbio and HLf recognize the same proteins. This clearly demonstrates that biotinylation did not change the reaction pattern of BLf or HLf. Also, the inhibition shown in lane $b$ of Fig. 2 (2) indicates that BLf and HLf recognize the same proteins. The lack of inhibition shown in lane B of Fig. 2 (1) indicates that BLf-bio bound proteins that were first bound to HLf by excluding HLf due to its higher binding affinity. The results of using the pepsin lysate of BLf as the inhibitor were similar to those of the control, indicating that pepsin disrupted the binding site of Lf for Jurkat cell receptor proteins. It has been shown that the oral administrational Lf hardly enters the blood in the intact form through the intestines, because most of the Lf was digested in the stomach or intestines (pepsin etc.) [14]. Therefore, the oral administration of Lf could not reach the small intestine in the intact form. These findings suggest that intact Lf does not have enough opportunity to act on intestinal mucosal immunity.

Lactoferrin is a glycoprotein that incorporates $\mathrm{N}$-glycosil-linked glycans containing $\mathrm{N}$-acetylneuraminic acid, galactose, mannose, fucose, $\mathrm{N}$-acetyl-D-glucosamine and $\mathrm{N}$-acetyl-D-galactosamine [21]. It is possible that these sugar components contribute to the binding of Jurkat cell 


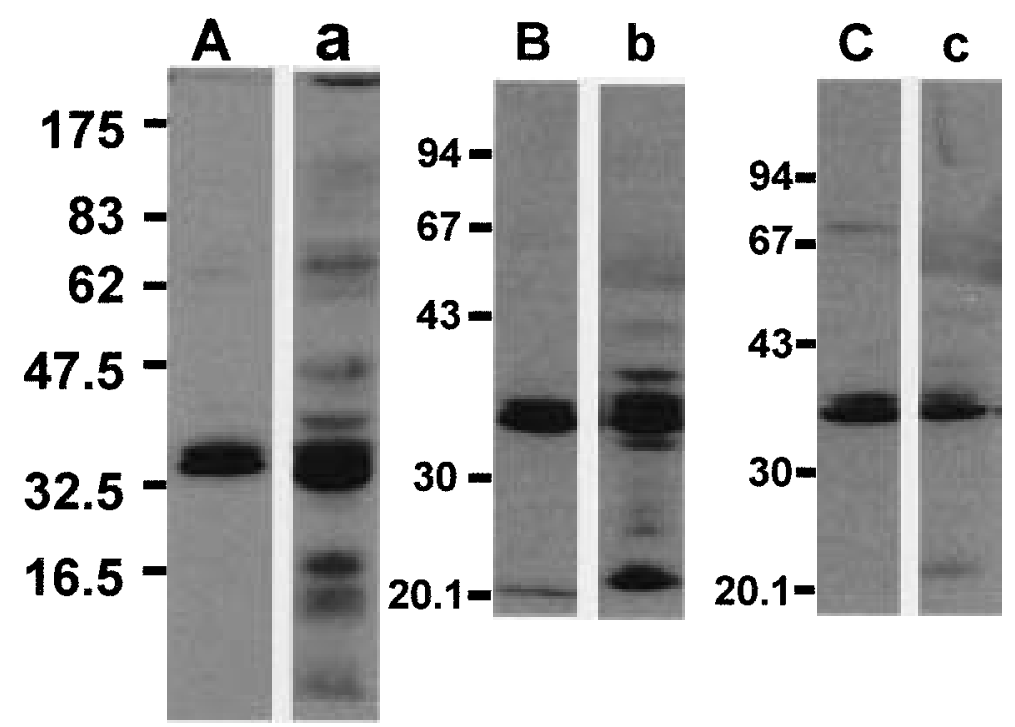

Fig. 3. Comparison of binding to membrane and cytosolic proteins of Jurkat cells between BLf-bio, BTf-bio and OTf-bio. The membrane (lane A, B, C) or cytosolic (lane $\mathrm{a}, \mathrm{b}, \mathrm{c}$ ) proteins of Jurkat cells were subjected to SDS-PAGE under reducing conditions and electrotransferred to PVDF membrane. After incubation with BLfbio (lane A, a), BTf-bio (lane B, b) or OTf-bio (lane C, c) at a concentration of $1 \mu \mathrm{g} /$ $\mathrm{m} l$, the binding proteins were detected with streptavidin-HRP. The positions of protein molecular mass standards are indicated at the left, in $\mathrm{kDa}$.

proteins. Therefore, a competitive inhibition assay was performed with these sugars as the inhibitors but there was no inhibition by $\mathrm{N}$-acetyl-D-glucosamine, $\mathrm{N}$-acetyl-D-galactosamine, $\mathrm{D}(+)$-mannose or lactose. These results indicate that these sugars are not involved in the binding of BLf to Jurkat cells.

The membrane proteins of Jurkat cells were extracted by the freeze/thawing method in order to destroy the cells physically, and the proteins were gathered from the pellets. There were many bands in the CBB-stained gel in which the membrane proteins of Jurkat cells were electrophoresed (Data not shown). There were only 2 membrane protein bands whose molecular weight was about $35 \mathrm{kDa}$ (lane A in Fig. 3), whereas among cytosolic proteins there were many bands in the vicinity of $35 \mathrm{kDa}$ (lane a in Fig. 3). These 2 membrane proteins are thought to be the Lf receptor. These components have lower molecular weights than those of other reported Lf receptor proteins in Jurkat cells [3, 16, 17], which have estimated molecular weights of around 105 $\mathrm{kDa}$. There are 2 likely reasons for the inability to detect $\mathrm{Lf}$ receptors on low-permeability cells. The first is that internalization of biotinylated Lf occurs before the reaction with the second ligand can take place. This hypothesis is supported by the finding that Jurkat cells can internalize bound Lf [4]. The second likely reason is that the receptor protein is not present on the cell surface under normal physiological conditions [8].

Bovine Lf, BTf and OTf are members of the transferrin family of proteins, and the homology of primary structure between them is about $60 \%$. Therefore, they are considered to be closely related evolutionarily, and may have similar biological functions. In the present study, to compare the binding pattern of BLf with those of BTf and OTf, far Western blotting with BTf-bio and OTf-bio was performed. Far Western blotting of membrane proteins of Jurkat cells with BTf-bio and OTf-bio showed 2 clear bands around $35 \mathrm{kDa}$ (lanes $\mathrm{B}$ and $\mathrm{C}$ in Fig. 3), a finding very similar to that obtained for BLf-bio. This suggests that BTf and OTf recognize the same proteins that BLf recognizes.

When antigens enter the host, various immune-related cells converge on the antigens at affected sites. T-cells, the most important cells in cell-mediated immunity, react specifically to the antigen, and are involved in inflammation but excessive immunoreaction injures tissues around affected sites. Control of macrophages and T-cells is an important element of anti-inflammatory processes. Neutrophils are the first immune-related cells to arrive at the affected site, followed by macrophages and lymphocytes. Because neutrophils arrive at the affected site at the beginning of inflammation and can produce $\mathrm{Lf}$, it is reasonable to speculate that Lf from neutrophils controls the function of macrophages and T-cells. Yoo et al. have studied effects of Lf on T-lymphocytes. It has been shown that interaction of BLf with excessively activated T-lymphocytes decreases production of IL-2, IL-4, IL-6 and TNF- $\alpha$ (in preparation). Further information about the BLf receptor is needed before BLf can be used to modulate the human immune system. There is a need to clarify the contribution of the Lf binding site to interaction with Jurkat cells and the mechanism of regulation of T-cells by binding of Lf. 
ACKNOWLEDGEMENT. This work was supported by the Japan-Korea Basic Scientific Cooperation Program.

\section{REFERENCES}

1. Arnold, R.R., Brewer, M. and Gauthier, J.J. 1980. Infect. Immun. 28: 893-898.

2. Bi, B.Y., Lefebvre, A.M., Dus, D., Spik, G. and Mazurier, J. 1997. Arch. Immunol. Ther. Exp. (Warsz) 45: 315-320.

3. Bi, B.Y., Leveugle, B., Liu, J.L., Collard, A., Coppe, P., Roche, A.C., Nillesse, N., Capron, M., Spik, G. and Mazurier, J. 1994. Eur. J. Cell Biol. 65: 164-171.

4. Bi, B.Y., Liu, J.L., Legrand, D., Roche, A.C., Capron, M., Spik, G. and Mazurier, J. 1996. Eur. J. Cell Biol. 69: 288-296.

5. Brock, J. 1995. Immunol. Today 16: 417-419.

6. Brock, J. 2002. Biochem. Cell Biol. 80: 1-6.

7. Dhennin-Duthille, I., Masson, M., Damiens, E., Fillebeen, C., Spik, G. and Mazurier, J. 2000. J. Cell Biochem. 79: 583-593.

8. Duthille, I., Masson, M., Spik, G. and Mazurier, J. 1998. Adv. Exp. Med. Biol. 443: 257-260.

9. Ellison, R.T., Giehl, T.J. and LaForce, F.M. 1988. Infect. Immun. 56: 2774-2781.

10. Groves, M.L. 1960. J. Am. Chem. Soc. 82: 3345-3350.

11. Harmsen, M.C., Swart, P.J., de Bethune, M.P., Pauwels, R., De Clercq, E., The, T.H. and Meijer, D.K. 1995. J. Infect. Dis. 172: $380-388$.

12. Hu, W.L., Mazurier, J., Sawatzki, G., Montreuil, J. and Spik, G. 1988. Biochem. J. 249: 435-441.
13. Kawakami, H., Dosako, S. and Lönnerdal, B. 1990. Am. J. Physiol. 258: 535-541.

14. Kuwata, H., Yip, T.T., Tomita, M. and Hutchens, T.W. 1998. Biochim. Biophys. Acta 1429: 129-141.

15. Laemmli, U.K. 1970. Nature (Lond.) 227: 680-685.

16. Legrand, D., van Berkel, P.H., Salmon, V., van Veen, H.A., Slomianny, M.C., Nuijens, J.H. and Spik, G. 1998. Adv. Exp. Med. Biol. 443: 49-55.

17. Mazurier, J., Legrand, D., Hu, W.L., Montreuil, J. and Spik, G. 1989. Eur. J. Biochem. 179: 481-487.

18. Mazurier, J., Montreuil, J. and Spik, G. 1985. Biochim. Biophys. Acta 821: 453-460.

19. Nagasawa, T., Kiyosawa, I. and Kuwahara, K. 1972. J. Dairy Sci. 55: 1651-1659.

20. Schryvers, A.B., Bonnah, R., Yu, R.H., Wong, H. and Retzer, M. 1998. Adv. Exp. Med. Biol. 443: 123-133.

21. Spik, G., Strecker, G., Fournet, B., Bouquelet, S., Montreuil, J., Dorland, L., van Halbeek, H. and Vliegenthart, J.F. 1982. Eur. J. Biochem. 121: 413-419.

22. Suzuki, Y.A., Shin, K. and Lonnerdal, B. 2001. Biochemistry 40: 15771-15779.

23. Tanaka, T., Omata, Y., Saito, A., Shimazaki, K., Yamauchi, K., Takase, M., Kawase, K., Igarashi, I. and Suzuki, N. 1995. Exp. Parasitol. 81: 614-617.

24. Tanaka, T., Omata, Y., Saito, A., Shimazaki, K., Igarashi, I. and Suzuki, N. 1996. J. Vet. Med. Sci. 58: 61-65.

25. Tsuda, H. and Sekine, K. 2000. Asian Pac. J. Cancer Prev. 1: 277-282. 